\section{Drs. Neogi and Felson reply}

\section{To the Editor:}

We thank Dr. Kirwan for his insightful comments regarding potential concerns about relying on a physician global assessment for rheumatoid arthritis (RA) disease activity assessment. We agree that "which physician" is providing his/her global assessment is an important determinant of the validity and reliability of such an outcome.

While we advocated the use of composite indices of disease activity over individual core set measures, we did argue that the physician global assessment may be considered a type of composite index in the setting of a clinical trial. In such a setting, the physician global assessment is informed by the systematic collection of data regarding tender and swollen joint counts, patient-reported pain and function, and laboratory measures. Indeed, in the clinical trial setting, the physician global assessment has been found consistently to be among the core set measures with the highest sensitivity to change ${ }^{1-3}$. However, this may not necessarily be the case in a clinic setting, where, in contrast to a clinical trial, a physician global assessment may not be informed by such comprehensive data. Differences in levels of experience and expertise as well as cognitive heuristics can contribute to variability in such assessments in the clinic.

We agree that a clinic-based measure of disease activity would provide rheumatologists with a systematic tool to monitor RA disease activity in clinical practice and could inform treatment decisions. The Disease Activity Score (DAS) ${ }^{4}$ is certainly a valid and reliable instrument for this purpose. However, one caveat regarding the use of DAS in the clinic is that swollen and tender joint counts used in the calculation of the DAS remain assessor-dependent and this assessment carries variability similar to that of the physician global assessment. Work is needed to examine whether implementing such quality of care measures in the clinic setting (outside a trial) has an influence on patient outcomes.

TUHINA NEOGI, MD, FRCPC; DAVID T. FELSON, MD, MPH, Clinical Epidemiology Research and Training Unit, Boston University School of Medicine, Suite X-200, 650 Albany Street, Boston, Massachusetts 02118, USA. Address reprint requests to Dr. Neogi.

\section{REFERENCES}

1. Neogi T, Xie H, Felson DT. Relative responsiveness of physician/assessor-derived and patient-derived core set measures in rheumatoid arthritis trials. J Rheumatol 2008;35:757-62.

2. Felson DT, Anderson JJ, Boers M, et al. The American College of Rheumatology preliminary core set of disease activity measures for rheumatoid arthritis clinical trials. The Committee on Outcome Measures in Rheumatoid Arthritis Clinical Trials. Arthritis Rheum 1993;36:729-40.

3. Pincus T, Amara I, Segurado OG, Bergman M, Koch GG. Relative efficiencies of physician/assessor global estimates and patient questionnaire measures are similar to or greater than joint counts to distinguish adalimumab from control treatments in rheumatoid arthritis clinical trials. J Rheumatol 2008;35:201-5.

4. van der Heijde DM, van 't Hof M, van Riel PL, van de Putte LB. Development of a disease activity score based on judgment in clinical practice by rheumatologists. J Rheumatol 1993;20:579-81.

J Rheumatol 2009;36:2; doi:10.3899/jrheum.080955 